\title{
Hydrology of peri-urban catchments: processes and modelling
}

\author{
Braud, I. ${ }^{(1)}$, Fletcher, T.D ${ }^{(2)}$, Andrieu, H. ${ }^{(3)}$ \\ ${ }^{(1)}$ Irstea, UR HHLY, Hydrology- Hydraulics, 5 Rue de la Doua, CS 70077, 69626 \\ Villeurbanne cedex, France \\ (2) Department of Resource Management and Geography, The University of Melbourne, 500 \\ Yarra Boulevard, Burnley, Victoria 3121, Australia \\ ${ }^{(3)}$ LUNAM Université, IFSTTAR, Département Géotechnique Eau et Risques and IRSTV- FR \\ CNRS 2488, CS 4, F-44344 Bouguenais, France
}

Corresponding author: Isabelle BRAUD, Irstea, UR HHLY, 5 Rue de la Doua, CS 70077, 69626 Villeurbanne cedex, France. Isabelle.braud@irstea.fr 


\section{Introduction}

Projections of population growth from the United Nations ${ }^{1}$ predict that $67 \%$ of the world population will live in urban areas by 2050. This urban sprawl inevitably leads to the development of previously natural or agricultural areas on the periphery of large urban centres (e.g. Meija and Moglen., 2010). We will refer to these areas using the word peri-urban. This word is most often used in Europe and Australia, where it refers to catchments made of a mixture of natural or agricultural lands, and urbanised areas. In the US, the word suburban is most commonly used, and it generally refers to residential areas with houses and gardens. We will use the word peri-urban in the remaining of the paper to cover both aspects.

These peri-urban areas are characterized by a high degree of heterogeneity and are "formed of a patchwork of urban, undeveloped (natural) and agricultural lands" (Andrieu and Chocat, 2004) in complex interactions (e.g. Santo Domingo et al., 2010). The spatial resolution of this landscape heterogeneity varies between urbanised areas, with the patch size governed by the urban cadastral parcel, and the arrangement of agricultural and forested areas, which will generally comprise larger parcels. The two types of areas - urban and agricultural/natural - are also characterized by different hydrologic response times. The creation of impervious areas, with hydraulically efficient drainage, will result in much faster drainage than in natural areas (e.g. Burns et al., 2012; Furusho et al., in press). Urbanization leads to new buildings and houses, and significant modification of water pathways through different networks such as roads, stormwater gutters and pipes, constructed channels, which may also interact with the network of potable water and sewer systems. This has a significant impact on the catchment delineation and drainage network (Jankowfsky et al., 2012; Rodriguez et al., 2013). In addition, peri-urban catchments tend to exhibit high rates of changes (e.g. Beighley et al., 2003; Radojevic et al., 2010; Jankowfsky, 2011).

Several studies have reported on the impact of urban sprawl on the water cycle and the condition of peri-urban rivers and aquatic ecosystems. The creation of urban infrastructure and in particular of urban drainage systems - has a significant impact on hydrologic and ecosystems functions, and often results in excess runoff, increases in diffuse pollution, whilst depleting groundwater and baseflows, thus increasing the vulnerability of these areas to floods, droughts and water quality problems within peri-urban rivers (e.g. Bras and Perkins, 1975; Chocat et al., 2001; Marsalek et al., 2007; Jacobson, 2011). Despite the fact that future

\footnotetext{
1 http://esa.un.org/unpd/wup/unup/
} 
development is considered designing stormwater drainage systems, the limits and negative consequences of the "end-of-pipe" urban are increasingly apparent. In catchments with separate drainage systems, the frequent discharge of stormwater - occurring whenever there is more than about $1 \mathrm{~mm}$ of rainfall - results in degradation of water quality, hydrology, geomorphology and ecological condition of receiving waters (Hatt et al., 2004; Walsh et al., 2005; Fletcher et al., 2013). In order to limit sewer network overflows in Combined Sewer Systems (CSSs), Combined Sewer Overflows (CSOs) are introduced, but this results in the discharge of polluted waters to receiving waters. This can lead to incision and erosion problems, which perturb the ecological status of the rivers (e.g. Randhir, 2003; Lafont et al., 2006).

In Europe, the Water Framework Directive (WFD) imposes constraints on the recovery of a "good ecological status" of rivers. The Flood Directive asks member states to map areas vulnerable to floods, and try to reduce this risk. Similar pressures exist around the world. This has several implications in terms of management of stormwater, meaning that alternatives to the "end-to-pipe" strategy are required (e.g. Booth et al., 2002; Matteo et al., 2006). Source-control stormwater techniques, which receive and deal with stormwater runoff (both in terms of flow and quality) at or close to its source, are increasingly the focus of stormwater management (Freni et al., 2010). This approach to stormwater management is often termed Water Sensitive Urban Design (WSUD; Wong, 2007), Low Impact Development (LID; Davis, 2005) or Sustainable Urban Drainage Systems (SUDS; CIRIA, 2000; Fletcher et al., 2008; Mikkelsen et al., 1996).

The management of water in peri-urban areas is thus a challenge for both research and practice. While the hydrology of urban and rural areas has been extensively studied, there is a comparative lack of data for peri-urban areas (Harremoës, 2002). Research challenges include the observation and monitoring of the hydrological cycle within mixed natural and artificial catchments, considering both water quantity and quality. Such catchments have a mix of fast and slow hydrologic responses, as a result of greatly differing flow paths (from areas which are baseflow dominated to those dominated by pipeflow). Tracking the evolution of the land use/practices in peri-urban areas also provides a rich area for research, with new capability to map changes appearing, especially in recent years with the increased spatial and spectral resolution of remote sensing imagery (e.g. Chormansky et al., 2008; Weng, 2012). The question of observation scale (both temporal and spatial) required to correctly document the hydrological cycle in those catchments must also be addressed, as must the development of measurement techniques and the definition of metrics to understand and quantify the impacts 
of human activities on the hydrological cycle (Braud et al., 2013; Hamel et al., 2013). Field observatories, devoted to the long-term monitoring of peri-urban catchments, including the evolution of land use are an important resource to advance this research field. Addressing these challenges is necessary to better understand and quantify the contributions of both natural and constructed sub-areas within peri-urban catchments, considering rainfall and soil conditions, as well as the spatial arrangement and hydraulic connection of impervious areas. It is only with this understanding that optimal stormwater management strategies can be developed, with the aim of mitigating impacts of urbanisation on peri-urban catchments (e.g. Hamel et al., 2013).

Many stormwater models have been developed specifically for modelling urban or rural areas. Modelling peri-urban areas is complicated by issues related to catchment discretization, representation of each of the different flow pathways, and the temporal nature of their response, with changes in land use and flow paths being liable to occur during the simulation periods, requiring an adaptation of hydrological models. Modelling of urban areas has often been dedicated to the dimensioning of hydraulic infrastructure (sewer networks, retention basins) and event-based models are often used for this purpose. In order to have an appraisal of the impact of urbanization on the whole hydrological cycle, including hydrological regime, high and low flows, continuous simulations are required, to predict consequences for water quality and for the flow regime more broadly (Fletcher et al. 2013). This leads to new questions in terms of process representation, catchment discretization and coupling of various processes. Such models are often used for quantifying the impact of land use change and urbanization on the hydrological cycle (e.g. Beighley et al., 2003; Ott and Uhlenbrook, 2004; Burns et al., 2005; Chormanski et al., 2008; Meierdiercks et al., 2010). The evaluation of those models and the quantification of the uncertainty in their results must also be addressed. These research topics become increasingly important as urban development occurs within the context of a changing climate. Understanding of this combined global change on the water cycle in urban and peri-urban areas, along with the performance of mitigation strategies, are crucial issues for hydrologists, urban planners and water systems managers.

\section{Content of the special issue}

This special issue of the Journal of Hydrology "Hydrology of peri-urban catchments: processes and modelling" includes 16 papers, which cover four main themes: (i) use of data sets and literature reviews to quantify the effects of urbanization and artificial networks on the 
hydrology of peri-urban catchments; (ii) use of very high and medium resolution remote sensing images and urban data banks to characterize peri-urban landscapes and water pathways; (iii) integrated modelling of peri-urban catchments using distributed hydrological models or statistical models. The fourth theme is transversal to the first three and gathers papers dealing with the use of source control stormwater management techniques and how their impact can be quantified at the scale of a whole catchment.

The first theme "use of data sets and literature review to quantify the impact of urbanization and artificial networks on the hydrology of peri-urban", comprises three papers. Braud et al. (2013) review a set of indicators used to assess the impact of urbanization on streamflow regimes, including statistical tests and characterization of high and low flows. They also propose methods to isolate the rapid contribution of sewer overflow devices on the total river discharge, and to quantify infiltration into sewer networks. The methods are tested using data from a long-term monitored French catchment. Using data from the same periurban catchment, Navratil et al. (2013), propose a method allowing quantification of the impact of sewer overflow devices and urban runoff on the geomorphology of small peri-urban river reaches. They highlight a global enlargement of urban rivers and a large impact of road sewers for catchments smaller than $5 \mathrm{~km}^{2}$. In the context of semi-arid climates, Gallo et al. (2013) show how runoff and its geochemical composition can be used to quantify the various contributions (surface, sub-surface flow) to the sewer and river networks. They also show the large impact of stormwater management on river discharge quantity and quality.

In the second theme "use of very high and medium resolution remote sensing images and urban data banks to characterize the peri-urban landscapes and the water pathways", four papers explore the potential of several data sources to describe the heterogeneity of peri-urban catchments. Rodriguez et al. (2013) compare the ability of three methods to delineate periurban sub-catchments and define the drainage networks. These include a traditional method of flow direction determination based on a Digital Elevation Model (DEM); a method exploiting the information present in urban data banks (sewer and road network, cadastral parcels); and a third method which uses constrained Triangular Irregular Networks (TINs). Three papers address the land use/land cover mapping of peri-urban catchments. Jacqueminet et al. (2013) explore and compare the potential of several methods and Very High Resolution (VHR) images for land cover mapping for use within distributed hydrological models. In particular, they focus on the quantification of imperviousness and vegetation cover. They show the interest of combining the various information sources for an improved description of land cover classes. Dams et al. (2013) also attempt to map imperviousness and its evolution 
through the use of medium resolution satellite images, which are more accessible than VHR images. They highlight a densification of urbanization and increase of urbanization between 1986 and 2003 in a Belgian catchment. They also show the impact of this modification on the water balance components. Finally, Aichele et al. (2013) explore the change in the form of peri-urban developments between 1950 and 2005 in Oakland county, Michigan, with an emphasis on imperviousness. They exploit cadastral (land tax) information (in particular land parcel size and land cover images) to show that, in the study area, land occupation is increasing at a faster rate than is imperviousness (with newer properties generally having lower impervious areas, and a lower rate of connection to the storm sewer). While perhaps an unusual case, this has some implications for hydrological models, especially when imperviousness is used as a surrogate of the runoff coefficient. It demonstrates the importance of considering directly connected imperviousness, rather than total imperviousness. This paper also makes the link with the third theme of the special issue, about "integrated modelling".

The third theme comprises various approaches to derive integrated models of periurban catchments: statistical models, use and/or adaptation of existing distributed models and development of new distributed models (6 papers). Isik et al. (2013) propose a hybrid model, based on Artificial Neural Networks (ANNs) and the Soil Conservation Service (SCS) Curve Number $(\mathrm{CN})$, to predict the effect of land use/land cover change on daily stream flow. Zhou et al. (2013) use the SWAT model, in combination with the CLU-E land use/land cover change model, to understand and quantify the hydrological responses to land use and land cover changes between 1985 and 2008, in two sub-catchments of the Yangtze River Delta (China). They find an $11 \%$ runoff increase, balanced by a similar decrease in base flow. The model results suggest a higher impact of runoff if imperviousness is increased from 15 to $25 \%$ of the catchments areas. Zhang et al.'s (2013) study deals with a completely artificial environment (an artificial park with natural, roads, drainage networks, etc.) in the surroundings of Beijing (China). They use a Dynamic Watershed Simulation Model (DWSM) to simulate the runoff and sediment transport processes from monitored and design storms and try to assess the impact of Best Management Practices (BMPs) on runoff and sediment yield. Furusho et al. (2013) adapted the ISBA-Topmodel, initially designed for monitoring high impact events in the south of France, to small peri-urban catchments. For that purpose, they propose a specific treatment of impervious areas and include infiltration into the sewer system. The model shows satisfactory performance, following its calibration to a French periurban catchment. Bach and Ostrowski (2013) propose a continuous integrated hydrological 
model of peri-urban catchments, taking explicitly into account rural and urban areas as well as the sewer system. They model the hydrological processes with time steps consistent with the response times of each surface type. The model is run continuously to assess the quality of receiving water in the context of the Water Framework Directive. Barron et al. (2013) use a process-based coupled surface water and groundwater model (MODHMS) to study the impact of urbanization on the water balance of a small Australian catchment, characterized with surface and groundwater interactions, and specific stormwater management practices. Due to the local groundwater configurations, the impact of urbanization leads to increases in recharge and drainage by the sewer system. This paper which also addresses source-control stormwater management, thus integrates well with the fourth theme, which deals with the "the use of source control rain water management techniques" and how the impact of local practices can be quantified at the whole catchment scale.

Three papers address this topic. Shuster and Rhea (2013) present an experimental study where a catchment was monitored several years before and after the application of source control stormwater techniques with control and treated sub-catchments. They also use statistical models to assess the efficiency of the source control treatment. Petrucci et al. (2013) propose a literature review of the impact of source control techniques on hydrology. This is illustrated with three French case studies and complemented with numerical studies using the SWMM model. They also use the model to compare various stormwater performance standards (flow-rate based versus volume-based regulations) and show that this choice has a significant impact on the resultant hydrological regime. Hamel et al. (2013) propose a complementary paper, using a literature review to examine the impact of urbanization and artificial networks on baseflow (as opposed to the normal focus on peak flows). In doing so, they identify the impediments to developing stormwater management strategies which preserve or restore natural baseflow processes.

\section{Conclusions and directions for future research}

In the introduction to the Journal of Hydrology special issue on urban hydrology, Andrieu and Chocat (2004) claimed that the time had come to develop anthropogenic or peri-urban hydrology. Since that time, significant effort has been dedicated to this topic. This special issue gathers research papers from various research groups and case studies around the world, showing that peri-urban catchments and the impact of urbanization on the hydrological cycle are crucial questions for many countries. The papers show that progress has been made to 
better understand these complex environments, as well as to monitor and model its hydrologic behaviour. However, many questions remain. In particular, with the move towards new decentralised stormwater management approaches, there is the need (i) to understand hydrological behaviour within peri-urban catchments and its consequences for risks to both humans and ecosystems; (ii) to understand the impact of these new source-control stormwater management approaches at all scales, from the site-scale to that of the whole catchment; (iii) to continue the ongoing effort in terms of integrated modelling so that models are able to predict the impacts of alternative stormwater management strategies on the flow regime and water quality of receiving waters in peri-urban catchments.

In terms of describing peri-urban catchments, VHR remote sensing images analysis show a great potential, offering new opportunities to map the relevant landscape objects (and particularly elements of the drainage network and how it alters flowpaths) in the peri-urban context. In addition, at least in Europe, the monitoring networks installed to control the compliance of the WFD will provide new data, which can be used for a further understanding of the hydrology of peri-urban catchments and further develop integrated models. In summary, while much progress has been made in the field of peri-urban hydrology, the same is expected to be true over the next few years.

\section{Acknowledgments}

This special issue would not have been possible without the help of the numerous reviewers who made very useful comments in order to improve the quality and focus of the various papers. We also thank the editorial office of Journal of Hydrology and the chief editor K. Georgakakos for their help in building and finalizing this special issue. I. Braud and $\mathrm{H}$. Andrieu acknowledge the help of the French National Research Agency (ANR) through the AVuPUR (Assessing the Vulnerability of Peri-Urban Rivers) project (contract ANR-07VULN-01). T. Fletcher acknowledges support by the Australian Research Council Future Fellowship Scheme (FT100100144).

\section{References}

Aichele, S., Andressen, J.A., 2013. Spatial and temporal variations in land development and impervious surface creation in Oakland County, Michigan, 1950-2005, J. Hydrol. 485, 96102, http://dx.doi.org/10.1016/j.jhydrol.2012.12.049 
Andrieu H., Chocat B., 2004. Introduction to the special issue on urban hydrology. Journal of Hydrology 299, 163-165.

Bach, M., Ostrowski, M., 2013. Analysis of intensively used catchments based on integrated modelling, J. Hydrol. 485, 148-161, http://dx.doi.org/10.1016/j.jhydrol.2012.07.001

Barron, O.V., Barr, A.D., Donn, J.M., 2013. Effect of urbanisation on the water balance of a catchment with shallow groundwater, J. Hydrol. 485, 162-176, http://dx.doi.org/10.1016/j.jhydrol.2012.04.027

Beighley, R.E., Melack, J.M., Dunne, T., 2003. Impacts of California's climatic regimes and coastal land use change on streaflow characteristics, Journal of the American Water Resources Association, 39(6), 1419-1433.

Booth, D.B., Hartley, D. and Jackson, R., 2002. Forest cover, impervious-surface area, and the mitigation of stormwater impacts, Journal of the American Water Resources Association, 38(3), 8356-845.

Braud, I., Breil, P., Thollet, F., Lagouy, M., Branger, F., Jacqueminet, C., Kermadi, S., Michel, K., 2013. Evidence of the impact of urbanization on the hydrological regime of a medium-sized periurban catchment in France, J. Hydrol. 485, 5-23, http://dx.doi.org/10.1016/j.jhydrol.2012.04.049

Bras R.L., Perkins F.E. 1975. Effects of urbanization on catchment response. J. of Hydraulics Division. Vol. 101, HY3 ,pp.451-466.

Burns, D., Vitvar, T., McDonnell, J., Hassett, J., Duncan, J., Kendall, C., 2005. Effects of suburban development on runoff generation in the Croton River basin, New York, USA. Journal of Hydrology, 311(1-4), 266-281.

Burns, M., Fletcher, T.D., Hatt, B.E., Ladson, A., Walsh, C.J., 2012. Hydrologic shortcomings of conventional urban stormwater management and opportunities for reform. Landscape and Urban Planning, 105, 230-240.

Chocat, B., P. Krebs, J. Marsalek, W. Rauch, and W. Schilling. 2001. Urban drainage redefined: from stormwater removal to integrated management. Water and Science Technology, 43, 61-68.

Chormanski, J., Van de Voorde, T., De Roeck, T., Batelaan, O., Canters, F., 2008. Improving distributed runoff prediction in urbanized catchments with remote sensing based estimates of impervious surface cover. Sensors, 8, 910-932.

CIRIA, 2000. Sustainable Urban Drainage Systems - Design Manual for Scotland and Northern Ireland, Dundee, Scotland. 
Dams, J., Dujardin, J., Reggers, R., Bashir, I., Canters, F., Batelaan, O., 2013. Mapping impervious surface change from remote sensing for hydrological modeling, J. Hydrol. 485, 84-95, http://dx.doi.org/10.1016/j.jhydrol.2012.09.045

Davis, A.P., 2005. Green engineering principles promote low-impact development. Env.Sci. \& Tech., 39: 338A-344A.

Fletcher, T.D., Deletic, A., Mitchell, V., Hatt, B.E., 2008. Reuse of urban runoff - a review of recent Australian advances and remaining challenges. J. Environ. Qual., 37(116-117): DOI:10.2134/jeq2007.0411.

Fletcher, T.D., Andrieu, H., Hamel, P., 2013. Understanding, management and modelling of urban hydrology and its consequences for receiving waters; a state of the art. Advances in Water Resources, Adv. Water Resour. 51, 261-279, http://dx.doi.org/10.1016/j.advwatres.2012.09.001 .

Freni, G., Mannina, G., Viviani, G., 2010. Urban Storm-Water Quality Management: Centralized versus Source Control. Journal of Water Resources Planning and Management, 136(2), 268-278.

Furusho, C., Andrieu, H., Chancibault, K., 2013. Analysis of the hydrological behavior of an urbanizing basin, Hydrologic Processes, in press, doi: 10.1002/hyp.9706.

Furusho, C., Chancibault, K., Andrieu, H., 2013. Adapting the coupled hydrological model ISBA-TOPMODEL to the long-term hydrological cycles of suburban rivers: Evaluation and $\begin{array}{llll}\text { sensitivity } \quad \text { analysis, Hydrol. } & \text { J }\end{array}$ http://dx.doi.org/10.1016/i.jhydrol.2012.06.059

Gallo, E.L., Brooks, P.D., Lohse, K.A., McLain, J.E.T., 2013. Land cover controls on summer discharge and runoff solution chemistry of semi-arid urban catchments, J. Hydrol. 485, 3753, http://dx.doi.org/10.1016/j.jhydrol.2012.11.054

Hamel, P., Daly, E., Fletcher, T.D., 2013. Source-control stormwater management for mitigating the effects of urbanisation on baseflow: a review, J. Hydrol. 485,

201-211, http://dx.doi.org/10.1016/i.jhydrol.2012.12.048 .

Harremoës, P., 2002. Integrated urban drainage, status and perspectives, Water Science and Technology, 45(3), 1-10.

Hatt, B. E., T. D. Fletcher, C. J. Walsh, and S. L. Taylor. 2004. The influence of urban density and drainage infrastructure on the concentrations and loads of pollutants in small streams. Environmental Management, 34, 112-124.

Isik, S., Kalin, L., Schoonover, J.E., Srivastava, P., Graeme Lockaby, B., 2013. Modeling effects of changing land use/cover on daily streamflow: An Artificial Neural Network and 
curve number based hybrid approach, J. Hydrol. 485, 103-112, http://dx.doi.org/10.1016/j.jhydrol.2012.08.032

Jacobson, C.R., 2011. Identification and quantification of the hydrological impacts of imperviousness in urban catchments: A review, Journal of Environmental Management, 92(6), 1438-1448.

Jacqueminet, C., Kermadi, S., Michel, K., Béal, D., Gagnage, M., Branger, F., Jankowfsky, S., Braud, I., 2013. Land cover mapping using aerial and VHR satellite images for distributed hydrological modelling of periurban catchments: application to the Yzeron catchment (Lyon, France), J. Hydrol., 485, 68-83.

Jankowfsky, S., 2011 Understanding and modelling of hydrological processes in small periurban catchments using an object oriented and modular distributed approach. Application to the Chaudanne and Mercier sub-catchments (Yzeron catchment, France). Ph D thesis, University of Grenoble, $331 \mathrm{pp}$.

Jankowfsky, S., Branger, F., Braud, I., Gironas, J., Rodriguez, F., 2012. Comparison of catchment and network delineation approaches in complex suburban environments. Application to the Chaudanne catchment, France, Hydrological Processes, in press, doi: 10.1002/hyp.9506.

Lafont, M., A. Vivier, S. Nogueira, P. Namour, and P. Breil. 2006. Surface and hyporheic oligochaete assemblages in a Friench suburban stream. Hydrobiologia, 564, 183-193.

Marsalek, J., Jiméénez-Cisneros, B.E., Karamouz, M., Malmquist, P.A., Gldenfum, J. and Chocat, B., 2007. Urban water processes and interactions. UNESCO IHP-VI program, UNESCO, Paris, 239 pp.

Matteo, M., T. Randhir, and D. Bloniarz. 2006. Watershed-scale impacts of forest buffers on water quality and runoff in urbanizing environment. Journal of the American Water Resources Association, 132, 144-152.

Meierdiercks, K.L., Smith, J.A., Baeck, M.L., Miller, A.J., 2010. Analyses of Urban Drainage Network Structure and its Impact on Hydrologic Response1. JAWRA Journal of the American Water Resources Association, 46(5), 932-943.

Meija, A.I., Moglen, G.E., 2010. Spatial distribution of imperviousness and the space-time variability of rainfall, runoff generation, and routing. Water Resources research, 46: W07509, doi:10.1029/2009WR008568.

Mikkelsen, P.S., Jacobsen, P., Fujita, S., 1996. Infiltration practice for control of urban stormwater. Journal of Hydraulic Research, 34(6): 827-840. 
Navratil, O., Breil, P., Schmitt, L., Grosprêtre, L., Albert, M.B., 2013. Hydrogeomorphic adjustments of stream channels disturbed by urban runoff (Yzeron River basin, France), J. Hydrol. 485, 24-36, doi:10.1016/j.jhydrol.2012.01.036

Ott, B., Uhlenbrook, S., 2004. Quantifying the impact of land-use changes at the event and seasonal time scale using a process-oriented catchment model. Hydrology and Earth System Sciences, 8(1), 62-78.

Petrucci, G. Rioust, E., Deroubaix, J.F., Tassin, B., 2013. Do stormwater source control policies deliver the right hydrologic outcomes? J. Hydrol. 485, 188-200, http://dx.doi.org/10.1016/j.jhydrol.2012.06.018

Radojevic, B., Breil, P., Chocat, B., 2010. Assessing impact of global change on flood regimes. International Journal of Climate Change Strategies and Management, 2(2): 167179.

Randhir, T., 2003. Watershed-scale effects of urbanization on sediment export: assessment and policy, Water Resources Research, 39(6), 1-13.

Rodriguez, F., Bocher, E., Chancibault, K., 2013. Terrain representation impact on periurban catchment morphological properties, J. Hydrol. 485, 54-67, http://dx.doi.org/10.1016/j.jhydrol.2012.11.023

Santo Domingo, N., Refsgaard, A., Mark, O., Paludan, B., 2010. Flood analysis in mixedurban areas reflecting interactions with the complete water cycle through coupled hydrologic-hydraulic modelling. Water Science and Technology, 62, 1386-1392.

Shuster W., Rea L., 2013. Catchment-scale hydrologic implications of parcel-level stormwater management (Ohio USA), J. Hydrol. 485, 177-187, http://dx.doi.org/10.1016/j.jhydrol.2012.10.043

Walsh, C.J., Fletcher, T.D., Ladson, A.R., 2005. Stream restoration in urban catchments through redesigning stormwater systemes: looking to the catchment to save the stream. Journal of the North American Benthological Society, 24(3), 690-705.

Weng, Q., 2012. Remote sensing of impervious surfaces in the urban areas: requirements, methods and trends. Remote sensing of environment, 117, 34-49.

Wong, T.H.F., 2007. Water sensitive urban design; the journey thus far. Australian Journal of Water Resources, 110(3): 213-222.

Zhang, X., Zhang, X., Hu, S., Liu, T., Li, G., 2013. Runoff and sediment modeling in a periurban artificial landscape: Case study of Olympic Forest Park in Beijing, J. Hydrol. 485, 
Zhou, F., Xu, Y., Chen, Y., Xu, C.H., Gao, Y., Du, J., 2013. Hydrological Response to Urbanization at Different Spatio-temporal Scales simulated by coupling of CLUE-S and the SWAT model in the Yangtze River Delta region, http://dx.doi.org/10.1016/j.jhydrol.2012.12.040 